\title{
Отдаленные результаты протезирования митрального клапана
}

\author{
Пукас Е. В., Лазоришинец В. В. \\ ГУ «Национальный институт сердечно-сосудистой хирургии имени Н. М. Амосова НАМН» (Киев)
}

\begin{abstract}
Целью исследования является изучение результатов отдаленного периода при протезировании митрального клапана (ПМК) и факторов улучшения качества жизни прооперированных пациентов.

В анализируемую группу включены 634 пациента с изолированным митральным пороком, находившихся на хирургическом лечении в Институте сердечно-сосудистой хирургии имени Н. М. Амосова.

Средняя продолжительность наблюдения составила 7,3 $\pm 0,9$ г. Основными показателями, изучавшимися на протяжении 10 лет, были выживаемость $-69,4 \%$, стабильность хороших и удовлетворительных результатов $-57,3 \%$, свобода от тромбоэмболических осложнений - 79,7\%, свобода от повторных операций - 95,4\%.

Протезирование митрального клапана следует выполнять у пациентов II-III функционального класса и при наличии синусового ритма. Пациенты должны находиться под постоянным диспансерным наблюдением, особенно группа риска.
\end{abstract}

Ключевые слова: митральный порок, протезирование митрального клапана, хирургическое восстановление правильного ритма, искусственное кровообращение.

Клапанные пороки сердца составляют около $25 \%$ всех заболеваний сердца $[1,2,5]$. Наиболее часто наблюдается поражение митрального клапана. Изолированный митральный стеноз, по данным хирургических стационаров [3, 5], встречается в 44-68\% случаев митральных пороков (МП). Среди пациентов с митральной недостаточностью неревматического генеза мезенхимальная дисплазия является причиной развития порока в $40 \%$ наблюдений, а в странах Европы и США этим заболеванием страдает до 5\% населения $[2,6]$.

Протезирование клапанов сердца является наиболее эффективным методом коррекции пороков сердца, который позволяют устранить субстрат патологических изменений, улучшить внутрисердечную гемодинамику и качество жизни пациентов [7,9].

Целью исследования является изучение результатов отдаленного периода протезирования митрального клапана (ПМК) и факторов улучшения качества жизни прооперированных пациентов.

В анализируемую группу включены 634 пациента с изолированным митральным пороком, находившихся на хирургическом лечении в Институте с 1 января 2005 до 1 января 2007 года. Средняя продолжительность наблюдения составила 7,3土0,9 г. Основными показателями, изучавшимися на протяжении 10 лет, были выживаемость - 69,4\%, стабильность хороших и удовлетворительных результатов - 57,3\%, свобода от тромбоэмболических осложнений - 79,7\%, свобода от повторных операций $-95,4 \%$.

Протезирование митрального клапана следует выполнять у пациентов II-III функционального класса и при наличии синусового ритма [8, 11-13]. После операции пациенты должны находиться под постоянным диспансерным наблюдением, особенно группа риска.

Материал и методы. В анализируемую группу включены 634 последовательно прооперированных пациента с изолированным митральным пороком, находившихся на хирургическом лечении в Национальном институте сердечно-сосудистой хирургии НАМН с 01 января 2005 года до 01 января 2007 года. Это составило $96,7 \%$ от числа выписавшихся на госпитальном этапе $(\mathrm{n}=656)$. Из исследования исключены пациенты с сопутствующим умеренным аортальным пороком. Мужчин было $229(47,1 \%)$, женщин - 335 (52,9\%). Возраст пациентов колебался от 18 до 71года (средний составил 53,1 18,5 года). $89(34,1 \%)$ пациентов принадлежали ко II классу по классификации NYHA, 199 (31,7\%) пациентов относились к III классу по классификации NYHA, $380(60,0 \%)$ - к IV классу. Основной этиологической причиной пороков явился ревматизм в сочетании с липоидозом, миксоматозом $(67,5 \%)[4,7]$. Средняя продолжительность наличия порока составила $17,3 \pm 4,9$ года. Кальциноз митрального клапана отмечался у $247(38,9 \%)$ больных, а средняя длительность наличия фибрилляции предсердий составила $3,1 \pm 0,9$ года.

Восстановление синусового ритма во время операции проводилось посредством радиочастотной абляции левого предсердия по варианту операции левого Лабиринта-3 у 29 (4,6\%) пациентов [12, 13]. При дилатации ЛП выполнялась дополнительно его редукция у $47(7,4 \%)$ пациентов посредством парааннулярной 


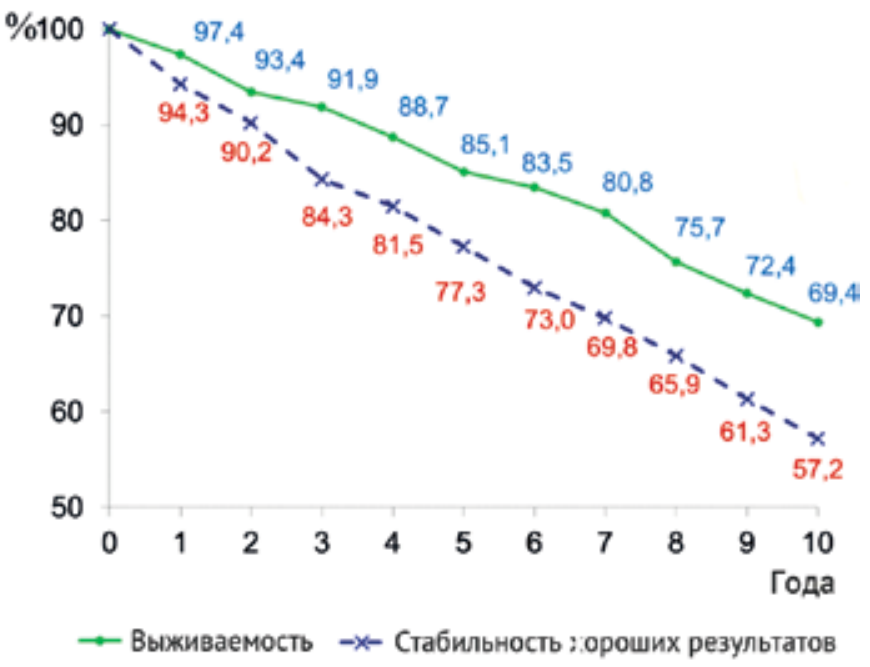

Рис. 1. Показатели выживаемости и стабильности хороших результатов

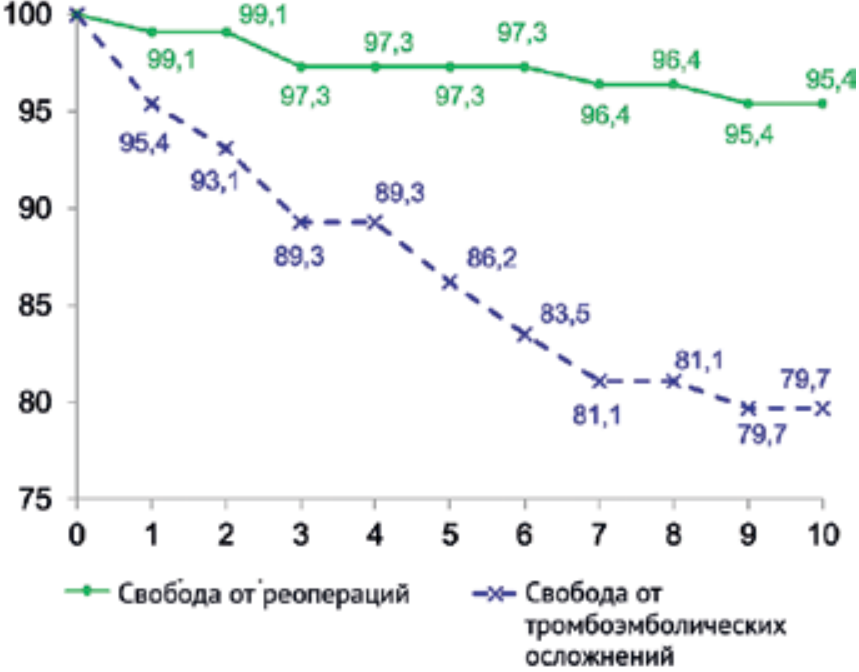

Рис. 2. Показатели свободы от реопераций и свободы от тромбоэмболических осложнений

ны прогрессирующей сердечной недостаточностью $31,1 \%$, тромбоэмболическими осложнениями $-37,8 \%$, прогрессирующей ИБС, гипертонической болезнью $16,2 \%$.

Структура летальных исходов при протезировании митрального клапана $(\mathrm{n}=135)$ представлена прогрессирующей сердечной недостаточностью - 33,3\%, тромбоэмболическими осложнениями $-31,3 \%$, прогрессирующей ИБС, гипертонической болезнью $-24,4 \%$.

Причинами повторных операций $(\mathrm{n}=9)$ были тромбоз протеза (панус, парапротезная фистула) $(n=5)$, поздний протезный эндокардит $(n=2)$, коррекция трехстворчатого порока $(n=2)$. Полная AV-блокада (c последующей имплантацией ЭКС) наблюдалась у 9 (1,6\%) пациентов.

Динамика эхокардиографических показателей на этапах лечения при сохранении подклапанных структур и редукции ЛП составила (n=34): фракция выброса

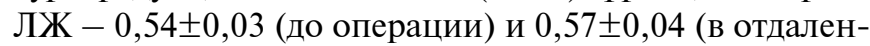

\section{Таблица 1}

Структура отдаленных результатов при протезировании митрального клапана показателями, изучавшимися на протяжении 10 лет, были выживаемость - 69,4\%, стабильность хороших и удовлетворительных результатов - 57,3\% (рис. 1), свобода от тромбоэмболических осложнений $-79,7 \%$, свобода от повторных операций $-95,4 \%$ (рис. 2).

Отдаленные результаты операции у пациентов IIIII класса NYHA значительно лучше, чем у пациентов IV класса (табл. 1).

Неудовлетворительные результаты при протезировании митрального клапана $(n=74)$ были обусловле-

\begin{tabular}{lccccc} 
& \multicolumn{5}{c}{ Отдаленный результат операции } \\
\cline { 2 - 6 } $\begin{array}{l}\text { NYHA, } \\
\text { клас }\end{array}$ & $\begin{array}{c}\text { хоро- } \\
\text { ший }\end{array}$ & $\begin{array}{c}\text { удовлетво- } \\
\text { рительный }\end{array}$ & $\begin{array}{c}\text { неудовлетво- } \\
\text { рительный }\end{array}$ & Умерли & Всего \\
\hline II-III & $\frac{194}{76,4 \%}$ & $\frac{28}{11,0 \%}$ & $\frac{5}{2,0 \%}$ & $\frac{27}{10,6 \%}$ & $\frac{254}{100,0 \%}$ \\
\hline IV & $\frac{100}{26,3 \%}$ & $\frac{103}{27,1 \%}$ & $\frac{69}{18,4 \%}$ & $\frac{108}{28,4 \%}$ & $\frac{380}{100,0 \%}$ \\
\hline Bсего & $\frac{294}{46,3 \%}$ & $\frac{131}{20,7 \%}$ & $\frac{74}{11,7 \%}$ & $\frac{135}{21,3 \%}$ & $\frac{634}{100,0 \%}$
\end{tabular}




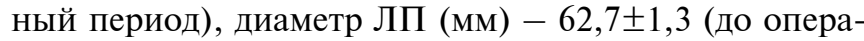
ции) и 52,3 1,5 (в отдаленный период).

Факторами риска в предоперационном периоде, влияющими на отдаленный результат, явились IV функциональный класс, фибрилляция предсердий, сопутствующая патология трехстворчатого клапана, атриомегалия левого предсердия (диаметр ЛП>6,0 см), фракция выброса ЛЖ $<0,45$, высокая легочная гипертензия (СДЛА $>70 \mathrm{mmHg}$ ), сопутствующее АКШ, прогрессирующая ишемическая болезнь сердца, левая вентрикуломегалия (конечно-систолический индекс левого желудочка $>95$ мл/ $\left.\mathrm{M}^{2}\right)$, женский пол, возраст больше 60 лет.

Выводы. Наилучшие результаты отдаленного периода после протезирования митрального клапана наблюдались у пациентов, прооперированных во II-III функциональном классе по NYHA и при наличии синусового ритма. Особое внимание в отдаленный период следует обратить на пациентов, которые находятся в группе риска. Комплексная реконструкция митрального порока с сохранением сократимости ЛЖ за счет сохранения его архитектоники является существенным фактором улучшения показателей отдаленного периода. Операцию Лабиринт, пластику ЛП следует выполнять для восстановления синусового ритма, а также уменьшения прогрессирования сердечной недостаточности и тромбоэмболических осложнений. После протезирования митрального клапана пациенты должны находиться под постоянным диспансерным наблюдением кардиолога по месту жительства.

\section{Литература}

1. Lazorishinec VV, Knyshov GV, Popov VV. Lechenie mitralnyh porokov serdca, oslozhnennyh fibrillyaciey predserdiy. Kiev; 2014. 101 s. (in Russian)

2. Orlov VI, Muzarbekova LI. Kardiohirurgicheskoe lechenie pacientov s priobretennymi porokami serdca: otdalennye rezultaty i klinicheskie faktory, vliyayuschie na nih. Ros. kardiol. zh. 2005:55(5):87-93. (in Russian)

3. Orlovskiy PI, Gricenko VV, Vavilova TV, i dr. Dva podhoda k korrekcii narusheniy gemostaza u bolnyh s mehanicheskimi iskusstvennymi klapanami serdca $\mathrm{v}$ otdalennye sroki nablyudeniya. Vestn. hirurgii. 2004;163(5):20-4. (in Russian)

4. Pribytkov MV. Otdalennye rezultaty odnomomentnoy hirurgicheskoy korrekcii fibrillyacii predserdiy i revmaticheskogo mitralnogo poroka [dissertaciya]. Moskva; 2004. 231 s. (in Russian)

5. Raskin VV. Atrioplastika levogo predserdiya u bolnyh s mitralnym porokom serdca [dissertaciya]. Moskva; 2006. 275 s. (in Russian)

6. Rychin SV. Operaciya "labirint" pri hirurgicheskom lechenii fibrillyacii predserdiy u bolnyh $\mathrm{s}$ porokom mitralnogo klapana: evolyuciya metodov i rezultaty [dissertaciya]. Moskva; 2004. 295 s. (in Russian)

7. ACC/AHA 2006 Guidelines for the Management of Patients With Valvular Heart Disease. J Am Coll Cardiol. 2006;48(3):733-812.

8. Avitall B, Kalinski A. Cryotherapy of cardiac arrhythmia: from basic science to the bedside. Heart Rhythm. 2015;12:2195-203.

9. Butchart EG, Payne N, Li HH, et al. Better anticoagulant controll improves survival after valve replacement. J Thorac Cardiovasc Surg. 2002;123:715-23.

10. Damiano RJ, Badhwar V, Acker MA, et al. The CUREAF trial: a prospective, multicenter trial of irrigated radiofrequency ablation for the treatment of persistent atrial fibrillation during concomitant cardiac surgery. Heart Rhythm. 2014;11:39-45.

11. January CT, Wann LS, Alpert JS, et al. 2014 AHA/ACC/ HRS guideline for the management of the patients with atrial fibrillation: a report of the American College of Cardiology/ American Heart Assosiation Task Force on Practice Guidelines and the Heart Rhythm Society. J Am Coll Cardiol. 2014;64:e1-76.

12. La Meir M. Surgical options for treatment of atrial fibrillation. Ann Cardiothorac Surg. 2014;3:30-7.

13. Masoudi FA, Calkins H, Kavinsky CJ, et al. 2015 ACC/ HRS/SCAI left atrial appendage occlusion device societal overview: a professional societal overview from the American College of Cardiology, Heart Rhythm Society, and Society for Cardiovascular Angiography and Interventions. Catheter Cardiovasc Interv. 2015;86:791-807.

14. Prabhu S, McLellan AJ, Walters TE, Sharma M, Voskoboinik A, Kistler PM. Atrial structure and function and its implications for current and emerging treatments for atrial fibrillation. Prog Cardiovasc Dis. 2015;58:152-67.

15. Stefanidis C, Nana AM, De Canniere D, Antoine M, Jansens J-L, Huynh, et al. 10-Year Experience With the ATS Mechanical Valve in the Mitral Position. Ann Thorac Surg. 2005;79:1934-8.

16. La Meir M. Surgical options for treatment of atrial fibrillation. Ann Cardiothorac Surg. 2014;3:30-7.

\title{
Remote results after mitral valve replacement
}

\author{
Pukas K. V., Lazorishinetz V. V. \\ National M. M. Amosov Institute of Cardiovascular Surgery National Academy of Medical Sciences of Ukraine (Kyiv)
}

Aim of investigation is to research properties of patients at remote period after mitral valve replacement (MVR). At analyzed group are included 634 patients with mitral valve diseases, which were treated by MVR in National Institute of cardio-vascular diseases named after Amosov from $1^{\text {st }}$ January 2005 to $1^{\text {st }}$ January 2007. Average being of research was $7,3 \pm 0,9$ yy. Following values of research at 10 year step: survival $69,4 \%$, stability of good results $-57,3 \%$, freedom from trombembolic events $-79,7 \%$, freedom from reoperations $-95,4 \%$. Plasty of LA was perfomed in $57(10,1 \%)$ patients. 
Maze procedure was occured in $39(6,9 \%)$ patients Concomitant tricuspid malformation (TV annuloplasty) was observed in 135 (23.7\%) patients. Concomitant CABG was observed in 93 (5.0\%) patients. Previous heart surgery (mainly closed mitral commissurotomy) had 129 (21.4\%) patients. Reoperations were occured: thomboses (panus, paraprost. fistula) of mitral prostheses $(n=5)$, endocardytis $(n=3)$. A-V blocade (pacemaker) was occured in $9(1.6 \%)$ patients.

Best results of mitral valve replacement were observed in remote period in patients at II-III NYHA class with presence of sinus rhythm. Patients must be followed-up with titghly observation especially risk group - IV functional class, atrial fibrillation, concominant tricuspid valve diseases, left atriomegaly (diameter of $6.0 \mathrm{~cm}$ or more), ejection fraction less than 0.45 , high pulmonary hypertension (PSPPA $>70 \mathrm{mmHg}$ ), CABG + progressive ischemic heart disease, left ventriculomegaly (ESVI $>95 \mathrm{ml} / \mathrm{m} . q)$, female, age more than 60 year.

Mitral valve replacement with operation Maze allows successfully renew sinus rhythm on a hospital stage, and stabilize it well during half-year after operation.

Key words: mitral valve disease, arrhythmia, surgical rhythm's renewal, cardio-pulmonary bypass.

\title{
Віддалені результати протезування мітрального клапана
}

\author{
Пукас К. В., Лазоришинець В. В. \\ ДУ «Національний інститут серцево-судинної хірургії імені М. М. Амосова НАМН» (Київ)
}

Набуті вади серця становлять 10-15\% всіх органічних уражень серця. Мітральну ваду серця мають 35-45\% усіх пацієнтів із набутими вадами серця. Найбільш частим етіологічним чинником виникнення мітральної вади серця виявилась ревматична хвороба серця, у тому числі в поєднанні з ліпоїдозом, кальцинозом, фіброзними змінами на клапанному апараті. Протезування мітрального клапана $є$ найбільш ефективним методом корекції мітральної вади серця.

Метою дослідження є вивчення результатів віддаленого періоду протезування мітрального клапана (ПМК) та факторів підвищення якості життя прооперованих пацієнтів.

В аналізовану групу включені 634 пацієнти з мітральною вадою, що знаходилися на хірургічному лікуванні в Інституті серцево-судинної імені М. М. Амосова в період з 1 січня 2005 року до 1 січня 2007 року. Середня

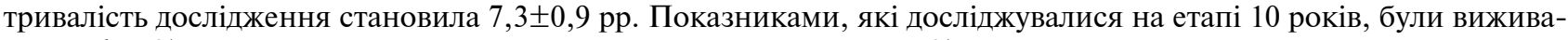
ність $(69,4 \%)$, стабільність гарних та задовільних результатів $(57,3 \%)$, відсутність тромбоемболічних ускладнень (79,7\%), відсутність повторних операцій $(95,4 \%)$.

Найкращі результати протезування мітрального клапана у віддаленому періоді спостерігалися у пацієнтів, прооперованих у II-III функціональному класі та з наявністю синусового ритму. Після операції пацієнти мають знаходитись під постійним диспансерним наглядом, особливо група ризику - пацієнти в IV функціональному класі, у яких наявна фібриляція передсердь, супутня патологія тристулкового клапана, атріомегалія лівого передсердя (діаметр ЛП $>6,0$ см), фракція викиду ЛШ $<0,45$, висока легенева гіпертензія (СТЛА $>70 \mathrm{mmHg}$ ), супутнє АКШ, прогресуюча ішемічна хвороба серця, ліва вентрикуломегалія (кінцево-систолічний індекс лівого шлуночка $>95$ мл/ $\mathbf{M}^{2}$ ), жіноча стать, вік більше 60 років.

Протезування мітрального клапана в поєднанні з операцією Лабіринт дозволяє успішно відновити правильний ритм на госпітальному етапі, зменшити прогресуючу серцеву недостатність і ризик тромбоемболічних ускладнень у віддаленому періоді.

Ключові слова: мітральна вада, протезування клапана, віддалений період ритму, хірургічне відновлення правильного ритму. 